\title{
AN INVESTIGATION ON THE ANTICANCER EFFECT OF SPIDER WEB IN HUMAN CERVICAL CELL LINE
}

\author{
Aslı Nur Özkan ${ }^{1}$, Oğuzhan Doğanlar² \\ ${ }^{1}$ Trakya University School of Medicine, Edirne, TURKEY \\ ${ }^{2}$ Department of Medical Biology, Trakya University School of Medicine, Edirne, TURKEY
}

\section{ABSTRACT}

Aims: The aim of this study is to investigate the anti-cancer and anti-proliferative effect of spider web extract, and mitochondrial apoptosis signaling response via gene expression levels belonging to caspase-3 depended apoptosis in both healthy Astrocyte and cancerous HeLa cell lines.

Methods: We used HeLa and C8-D1A Astrocyte type I clone cell lines as the human cervical cancer and healthy cell line, respectively. We treated the cells with spider web extract and performed MTT assay. IC50 was calculated by probit analysis. Molecular fluorescence staining and TALI cytometer measurements were also applied. The response of the mitochondrial apoptosis pathway to spider web extract treatment was analyzed by the qRT-PCR assay.

Results: The spider web extract administered in different concentrations to the HeLa cell line reduced cell viability at a statistically significant level after 24 hours of application. In the astrocyte cell line, the spider web extract did not cause statistically significant cell death. In the analysis of gene expressions, a strong mitochondrial apoptosis signaling was observed.

Conclusion: While spider web extract does not cause any cytotoxic effects on healthy cell lines, it causes a strong fatal effect in cancer cell line. In addition, IC50 dose of the spider web extract is satisfying compared to many other natural products in the market which have anti-cancer effects. Spider web extract causes a programmed cell death by following death signaling pathways.

Keywords: Spider, in vitro, cervical cancer

\section{INTRODUCTION}

Cervical cancer is the fourth most common type of cancer, estimated to affect one million women worldwide (1). Cervical cancers constitute $13.4 \%$ of deaths caused by female genital tract cancers (2). When it is detected early, there is a chance of complete recovery. However, if it is treated, the prognosis is poor. Rapid proliferation, resistance to treatment, early and late metastases as well as poor diagnosis are the causes of its lethal course. The need for new or supportive treatment methods has risen due to problems such as the long-term toxic effects of the current drugs. This reduces the chance of success in the treatment. The biggest problem encountered with chemotherapeutic agents is the rapid development of irreversible drug resistance by cancer cells $(3,4)$.
According to recent studies, spider venom and its derivatives such as peptides may have anti-cancer effects by inducing cell cycle arrest and apoptosis, inhibiting invasion, metastasis, angiogenesis, also blocking specific transmembrane channels. The researchers studied with spider venom or the spider itself (5-7). However, there is no study about anti-cancer effects of spider web in cancer cell lines to the best of our knowledge.

The spider web is a natural product that is being used in the Thrace Region and Bulgaria for the purpose of treatment of late-healing or deep wounds. It has been thought to have certain substances which play a role in controlling cell proliferation and inflammatory processes (8). Therefore, we extracted the spider web with 
different methods and analyzed it using liquid chromatography- tandem mass spectrometry (Lc-MS/MS). According to our previous study, there are various phenolic substances such as gallic acid, trans caffeic acid, naringin and melatonin at a very high level in the spider web and they are preserved despite natural events such as sunlight, wind or rain (TurkPatent, 2017/19916) (Table 1) (8). These substances play active roles in breaking the drug resistance in cancer cell lines that show multi-drug resistance and also, naringenin and quercetin are the most known members of the flavonoid family (9). Therefore, we hypothesized that spider web extract (SWE) can be an apoptosis activator and have anti-proliferative effects in cervical cancer cell lines. Additionally, it may be an anti-oxidant for healthy cells.
The aim of this study is to investigate the anti-proliferative, anti-cancer and apoptotic effects of the SWE on HeLa cell lines and to find the IC50 dose. In addition, we also studied endogenous apoptosis genes at the gene expression level and the mechanism by which the possible apoptotic effect of the extract induced. Finally, we applied the determined doses to healthy astrocyte cell lines and investigated its cytotoxicity.

Table 1: Phenolic substances, catecholamines and plant stress hormones detected in spider web extract with different alcohols.

\begin{tabular}{lcrr}
\multicolumn{4}{c}{ Polyphenolic Contents of Spider Web } \\
\hline Phenolic Substance & $\boldsymbol{R T}^{*}$ & Response & Concentration $(\mathbf{n g} / \mathbf{m l})$ \\
\hline Gallic Acid & 0.534 & 1345 & 41.3478 \\
Catechin & 0.539 & 171 & 10.5757 \\
Protocatechuic Acid & 0.556 & 48444 & 790.1062 \\
2,5-Dihydroxybenzoic Acid & 0.564 & 13569 & 606.5906 \\
Trans-Caffeic Acid & 0.607 & 9409 & 89.1363 \\
Trans-p-Coumaric Acid & 0.607 & 292 & 103.6793 \\
Naringin & 3.983 & 407 & 41.4550 \\
Quercetin & 4.130 & 27798 & 361.0320 \\
Trans-Sinapic Acid & 4.138 & 38 & 195.4869 \\
\hline Catecholamines and Hormones & $\mathbf{R T}$ & Response & Concentration $\mathbf{( n g / m l )}$ \\
\hline Melatonin & 4.186 & 81 & 3.9153 \\
Salicylic Acid & 3.745 & 2109 & 42.2579 \\
Abscisic Acid & 4.197 & 75 & 2.4156 \\
Jasmonic Acid & 4.373 & 14 & $\mathbf{1 . 5 5 3 1}$ \\
Indole-3-Acetic Acid & 3.805 & 17 & 23.7142 \\
\hline
\end{tabular}

${ }^{\star} R T$ : Response Time

\section{MATERIAL AND METHODS}

\section{The extraction of spider web}

In the study, we extracted $478 \mathrm{mg}$ of spider web with a 3:1.5:1.5 v/v isopropyl alcohol (Sigma W292907), ultra-pure water, Acetonitrile (Sigma 271004) in a heating magnetic stirrer at $50{ }^{\circ} \mathrm{C}$ for 45 minutes. We centrifuged the final volume of $40 \mathrm{ml}$ of this extract at 5000 rpm for 10 minutes, after the supernatant was passed through a syringe tip $(45 \mu \mathrm{m})$ to obtain a final volume of $12.5 \mathrm{ml}$ of the extract. We blew off the extract completely, using a hotplate and stocked the obtained product with water. This stock was used in all studies within 1-2 days of storage at $4^{\circ} \mathrm{C}$ in the dark, while the other part was divided into two equal solutions and stored at $-20^{\circ} \mathrm{C}$ and $-80^{\circ} \mathrm{C}$ for possible future use. 


\section{Culture and passage of the cells}

In the study, we used HeLa (ATCC ${ }^{\oplus}$ CCL2 ${ }^{\mathrm{ix}}$ ) cell line and brain astrocyte C8-D1A Astrocytic type I clone (ATCC ${ }^{\circledast}$ CRL-2541 ${ }^{\mathrm{Tm}}$ ) cell line as the human cervical cancer cell line and healthy cell line, respectively. Cell lines were cultured in the laboratories of Medical Biology Department in Trakya University. We cultured the cel1s grown in DMEM: F-12 Medium (ATCC ${ }^{\circledR} 30-2006^{\mathrm{rm}}$ ) containing heat-inactivated 10\% FBS (Gibco Life Technologies), $2 \mathrm{mM}$ L-glutamine (Gibco-Life Technologies) and $1 \%$ penicillin/streptomycin (Invitrogen, Life Technologies) in sterile incubators at $37^{\circ} \mathrm{C}$ and the presence of $5 \% \mathrm{CO} 2$. All the studies started from the 5 th passage of the cell lines and the study was terminated at 20th passage maximum.

\section{MTT assay and determination of IC50 dose}

In this study, we seeded HeLa cell line and the C8D1A cell line with multi-pipettes at 10,000 to 15,000 well during application in 96-well culture plates. At the end of one night (about 16 hours), we applied spider web extracts, and left them for incubation for 24 and 48 hours. In the MTT viability analyzes, the groups were composed of 6 wells, and in these groups, there were control groups containing solvent. After the first dose of SWE was made with 100-fold dilution, we used it in 9 different concentrations by serial dilution with solvent by $50 \%$ percent. We performed MTT assay after incubation for cell survival (viability) analysis. For this analysis, we pipetted the "Yellow tetrazolium MTT (3-(4,5-dimethylthiazolyl-2)-2,5-diphenyltetrazolium bromide)" test solution, prepared at a dose of $5 \mathrm{mg} / \mathrm{ml}$, equally to all wells as $20 \mu \mathrm{l} /$ well. Then, we incubated the plates for $2-4$ hours. After the incubation, we completely removed the medium in the wells with a multi-pipet so as not to damage the cell line adhered to the base. We added 200 $\mu \mathrm{l}$ of ultra-pure DMSO to each medium and incubated for 2 hours. Plates from the incubator were read spectrophotometrically at 492 and $570 \mathrm{~nm}$ wavelength with a Multiskan GO microplate reader. The value obtained from the control group was determined as $100 \%$ viability and the comparative mortality rate was determined based on this value. IC50 dose was calculated by probit analysis.

\section{Molecular fluorescence staining}

In the study, we used the NucBlue ${ }^{\circledast}$ Live ReadyProbes ${ }^{\oplus}$ to monitor apoptosis induction and nuclear morphology, CM-H2DCFDA staining for oxidative stress, and CellEvent ${ }^{\mathrm{TM}}$ Caspase-3/7 Green molecular probe for caspase-dependent apoptosis detection. For fluorescence staining, we plated HeLa cells to 24 -well plate as
$5 \times 104$ cells/well. The following day, we treated IC50 dose of the SWE to all cells except for the control group. After 24 hours of incubation, we labeled the first cell group with $5 \mu \mathrm{l}$ CellEvent ${ }^{\mathrm{rm}}$ Caspase-3/7 Green Detection Reagent, the second group with four drops of NucBlue ${ }^{\circledast}$ Live ReadyProbes ${ }^{\oplus}$ Reactant (Thermo Scientific ready-made probe guides) and $10 \mu \mathrm{l}$ CM-H2DCFDA and incubated the plate for 30 minutes at $37^{\circ} \mathrm{C}$. Images were obtained with 40X magnification on a Zeiss Axio Vert. A1 fluorescence microscope which has a DAPI filter for NucBlue ${ }^{\oplus}$ and FITC filter for both caspase 3/7 and CM-H2DCFDA. We performed each staining experiment on living cells.

\section{TALI cytometer measurements}

We also determined the apoptotic properties of SWE on human cervical cancer via Annexin V/PI staining with image-based cytometer. For this purpose, cells were cultured $25 \mathrm{~cm}^{2}$ cell culture flask and then incubated them for 24 hours. We used Tali ${ }^{\circledast}$ Image Cytometer (Life Technologies, USA) to observe the apoptotic and cell cycle effects of the SWE. At the end of the treatment, we removed the mediums in the flasks. We incubated these flasks for 5 minutes with $3 \mathrm{ml}$ of trypsin EDTA and harvested the cells by automatic pipetting into Eppendorf tubes and centrifuged the tubes at $1000 \mathrm{rpm}$ for 2.5 minutes. We completely withdrew the upper trypsin and supernatant and used the subcellular cells for analysis. The experiments to determine the apoptosis level by Tali cytometry were done by using Tali ${ }^{\circledast}$ Apoptosis Kit Annexin V Alexa Fluor ${ }^{\circledast} 488$ and Propidium Iodide (Life Technologies). According to the kit procedure, we suspended the cells remaining at the bottom of the tube in $1 \mathrm{ml} 1 \mathrm{X}$ Annexin binding buffer, $300 \mu \mathrm{l}$ of this mixture was taken and vortexed by adding $5 \mu \mathrm{l}$ of Annexin V Alexa Fluor ${ }^{\circledR} 488$ (Component A) per $100 \mu \mathrm{l}$. Afterwar$\mathrm{ds}$, we incubated the mixture at room temperature for 20 minutes in the dark. After centrifugation at $1000 \mathrm{rpm}$ for $2.5 \mathrm{~min}$, we discarded the supernatant and we suspended the cells at the bottom again with $100 \mu \mathrm{L}$ of ABB. We mixed this mixture with $1 \mu \mathrm{L}$ of Tali ${ }^{\circledast}$ Propidium Iodide (PI, component B) solution and incubated for 1-5 minutes in the dark. After the incubation, we took out $25 \mu \mathrm{l}$ of the mixture in the tubes to the slides in the prepared chitin, and Tali apoptosis analysis option for apoptosis and PI cell cycle analysis option for cell cycle were selected and read with the instrument software. In the analysis with Tali, each group was read by counting 20 different areas and each group was studied as 5 repetitions and 5 different slides for each repetition. 
Gene expression studies (For mitochondrial apoptosis pathway)

\section{RNA isolation}

We used total RNA PureLink ${ }^{\circledast}$ RNA Mini Kit (Life Sciences, USA) for isolation of total RNA from cell lines treated with SWE according to the kit protocol. We removed the cells from the flasks using $3 \mathrm{ml}$ trypsin, centrifuged and removed the supernatant. Then, we treated them with lysis buffer $+1 \% 2$-mercaptoethanol, prepared in $1 \mathrm{ml} \mathrm{kit,} \mathrm{and} \mathrm{transferred} \mathrm{to} \mathrm{the} \mathrm{spin} \mathrm{column.}$ After centrifugation at $12000 \mathrm{G}$ for 15 seconds at $25^{\circ} \mathrm{C}$, we removed the bottom part from the spin column. We added 700 microliters of wash buffer I and centrifuged at $25^{\circ} \mathrm{C}$ for 12 seconds at $12000 \mathrm{G}$. We followed the same procedure after adding 500 microliters of wash buffer II. After the lower columns were discarded, we centrifuged the cells at $12000 \mathrm{G}$ for 2 minutes and then, we passed the cells through special columns and collected the RNAs attached to the columns into the Eppendorf tube with purified water after washing the columns with the washing solution provided in the kit and cleaning the other compounds. We measured RNA quantity iso- lated from cell lines by using Qubit ${ }^{\circledast}$ Fluorometer (Invitrogen, USA). We equalized all RNA quantities with DNA, RNA-free ultra-pure water (Sigma, USA). We performed cDNA synthesis by the equalized RNAs by using High Capacity cDNA Reverse Transcription Kit (Applied Biosystems) with PCR conditions as follows: Step 1: $25^{\circ} \mathrm{C}, 10 \mathrm{~min}$; Step 2: $37^{\circ} \mathrm{C}, 120 \mathrm{~min}$; Step 3: 85 ${ }^{\circ} \mathrm{C}, 5 \mathrm{~min}$. The resulting cDNAs were stored at $-20^{\circ} \mathrm{C}$ for future analysis.

\section{qRT-PCR Analysis}

In our study, we studied the intrinsic apoptosis signaling (Mitochondrial pathway): Caspase 3, Caspase 8, BAX, BCL-2, PUMA, NOXA, P53, Cytochrome C and Apaf 1 genes. These cDNAs were amplified in qPCR according to SYBR Green qPCR Mastermix protocol using ABI Step One Plus real-time PCR using the specific primers and PCR conditions given in Table 1 in 96well plates. The Ct values of the peaks which were obtained during the amplification were used to determine the gene expressions and were calculated by the $\Delta \Delta \mathrm{Ct}$ method. GAPDH, $18 \mathrm{~S}, \beta$-actin specific control primers were used as endogenous control.

Table 2: Specific primers gene sequences and PCR conditions of the study.

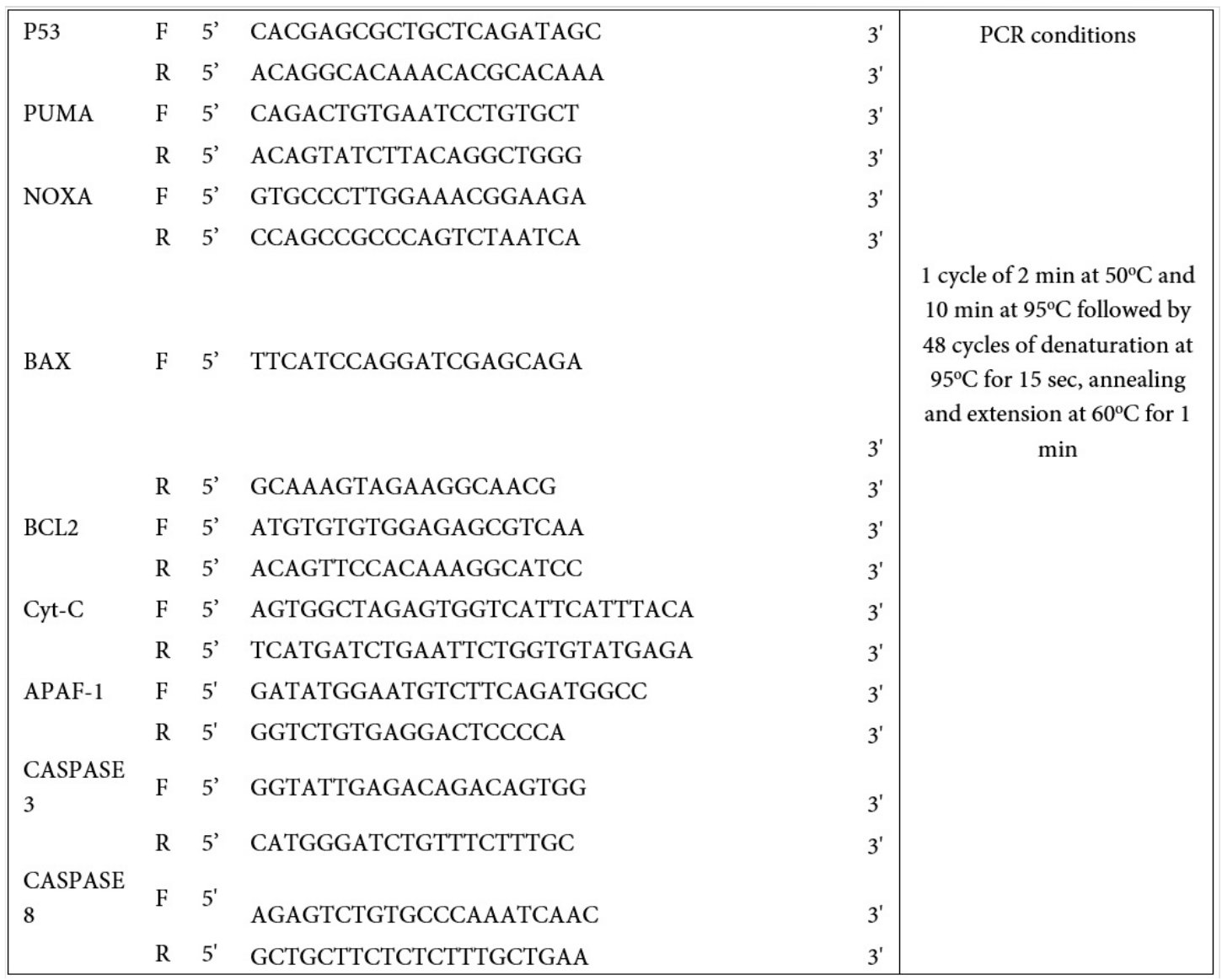




\section{Statistical analysis}

The differences between the cell numbers determined by Tali and the averages of the expression values obtained by the $\Delta \Delta \mathrm{Ct}$ method in qRT-PCR array were determined by one-way ANOVA and Student's T-test, and the groups of means were determined by the Duncan's test according to the status of the study data. Mean \pm standard deviation, numbers and percentages were used as descriptive statistics. We used SPSS 20 statistical package program in the study. A p-value of $<0.05$ was evaluated as statistically significant.

\section{RESULTS}

The SWE administered with different concentrations in the HeLa cell line reduced cell viability at a statistically significant level after 24 hours of application $(\mathrm{FHeLa}=$ 28.44, sd $=9-40, \mathrm{p}<0.0001$ ) (Figure 1 ). We determined the highest viable cell ratio as $65.99 \pm 1.76 \%$ for 3.125 $\mu \mathrm{g} / \mathrm{ml}-\mathrm{SWE}$ after 24 hours, while only $45.36 \pm 3.18 \%$ of the cells remained alive at $400 \mu \mathrm{g} / \mathrm{ml}$ concentration. We determined that the cell death was dependent on the dosage, and the correlation coefficient was -0.635 and the significance level was $\mathrm{p}=0.049$.

In the astrocyte cell line, the SWE did not cause any statistically significant cell death (FAstrocyte $=1.305$; standard deviation $(\mathrm{sd})=9-50, \mathrm{p}=0.258)$ (Figure 1).
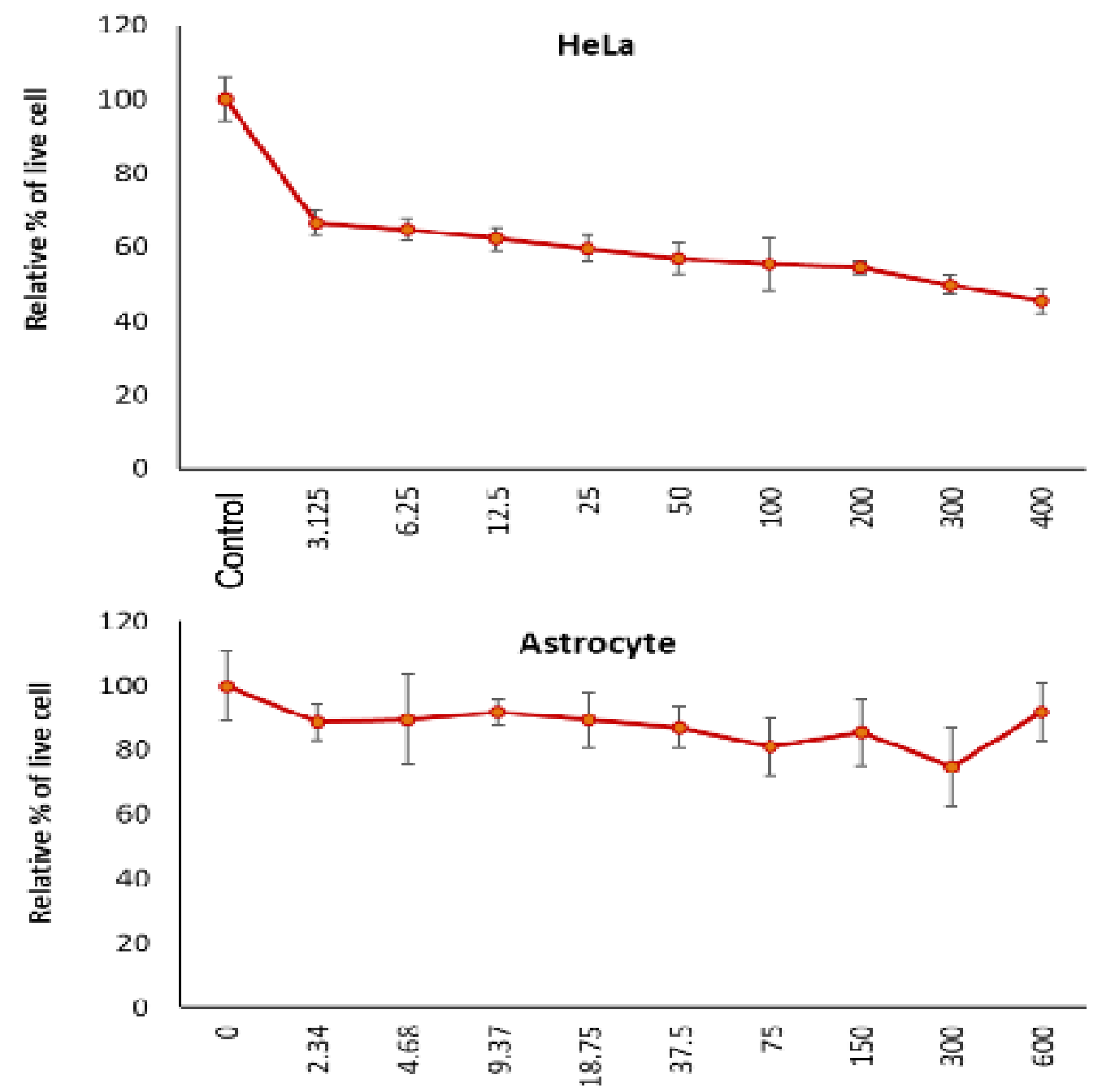

\section{Concentrations $(\mu \mathrm{g} / \mathrm{ml})$}

Figure 1: The effect of application of SWE for 24 hours on cell viability in HeLa and healthy astrocyte cell lines MTT test, data \% Viability mean \pm standard deviation. 
The IC50 value for the spider web extract was determined as $291.471 \mu \mathrm{g} / \mathrm{ml}$ and this dose was used in the following sections of the study.

As a result of the MTT test on HeLa cell lines, we determined only the living and dead cell ratios of the SWE and solvent (control) application in the study. We also performed TALI image-based cytometer analysis to determine whether the death of the cell lines by SWE were based on apoptosis.
Among the cells which were stained by using Annexin V-Alexa Fluor ${ }^{\circledast}$ 488, Propidium Iodide and Tali ${ }^{\circledR}$ Apoptosis Test Kit, dead or late apoptotic cells were red or yellow fluorescence, apoptotic cells were green fluorescence. We performed the analysis using the instrument software and the results are given in Figure 2.
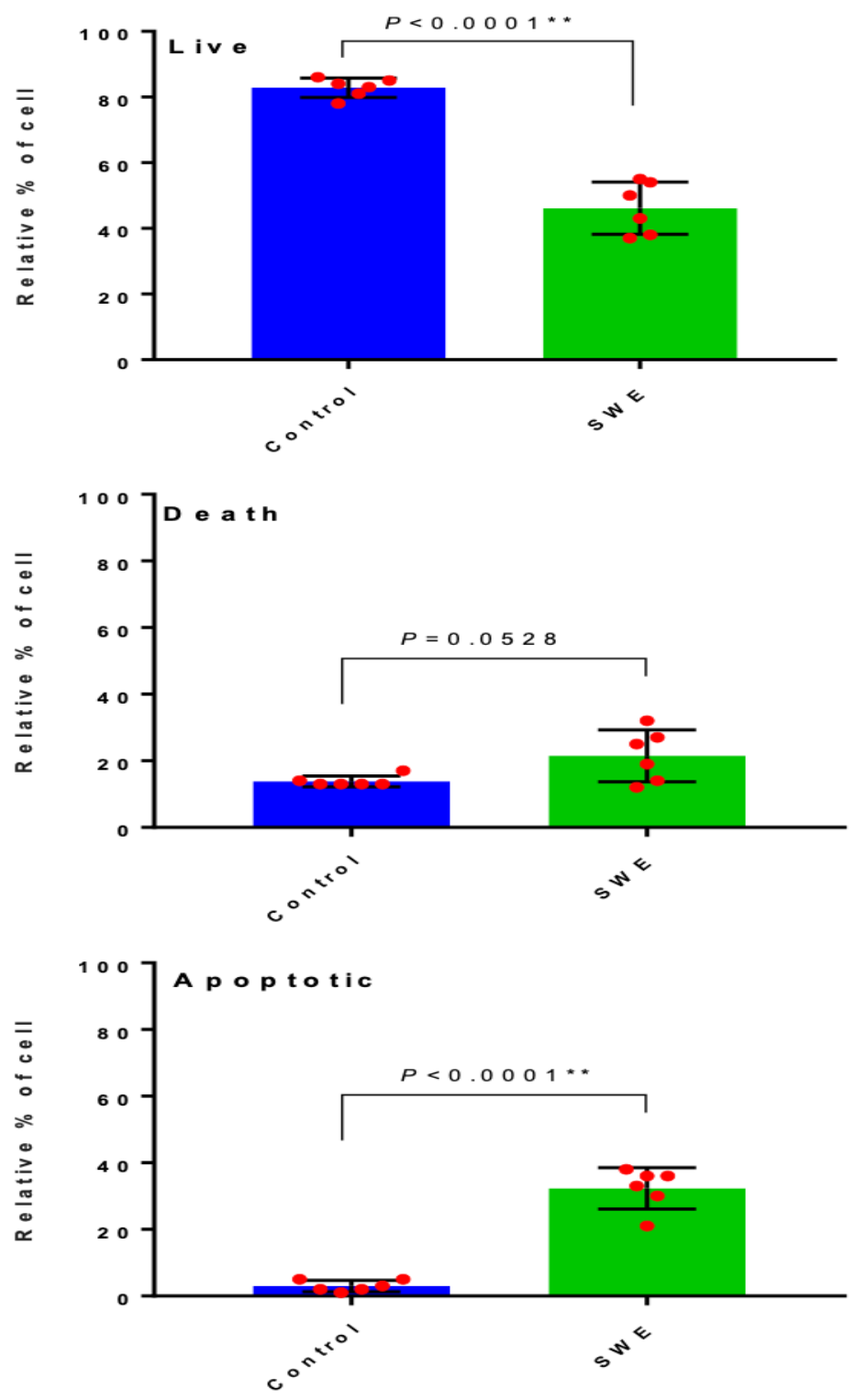

Figure 2: The percentages of living, dead and apoptotic cells detected in the HeLa peripheral cervical cancer cell line in a TALI image-based cytometry analysis. All data are given as the mean values of the percentages for each group $\pm s d . n=6$; Student's T-test $p \leq 0.05$. (SWE: Spider web extract) 
As a result, spider web application decreased the number of live cells in HeLa cells by a statistically significant ( $p<0.0001$, Figure 2$)$ level compared to control group $(82.83 \%)$ and the alive cell ratio was found to be $46.16 \%$ after 24 hours. Propidium iodide positive cells showed dead cells and the dead cell ratio was determined as $13.83 \%$ in the control group, to $21.5 \%$ in the SW group. However, no statistically significant difference was found between the groups. SWE increased the number of apoptotic cells at a statistically significant $(\mathrm{p}<0.0001$, Figure 2) level compared to the control, and the apoptotic cell ratio was $3 \%$ at the control, whereas $32.33 \%$ of the SWE cells showed apoptosis.
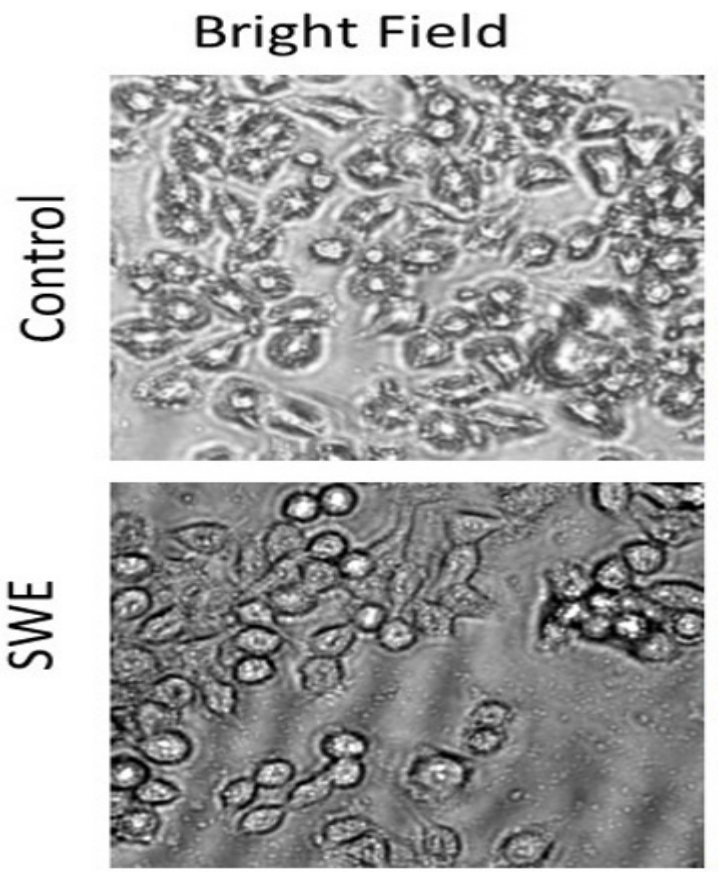

In the analysis of TALI cytometer, SWE caused a strongly programmed cell death. In order to support this analysis, the cells were stained with different substances and images were given in Figure 3 and 4.

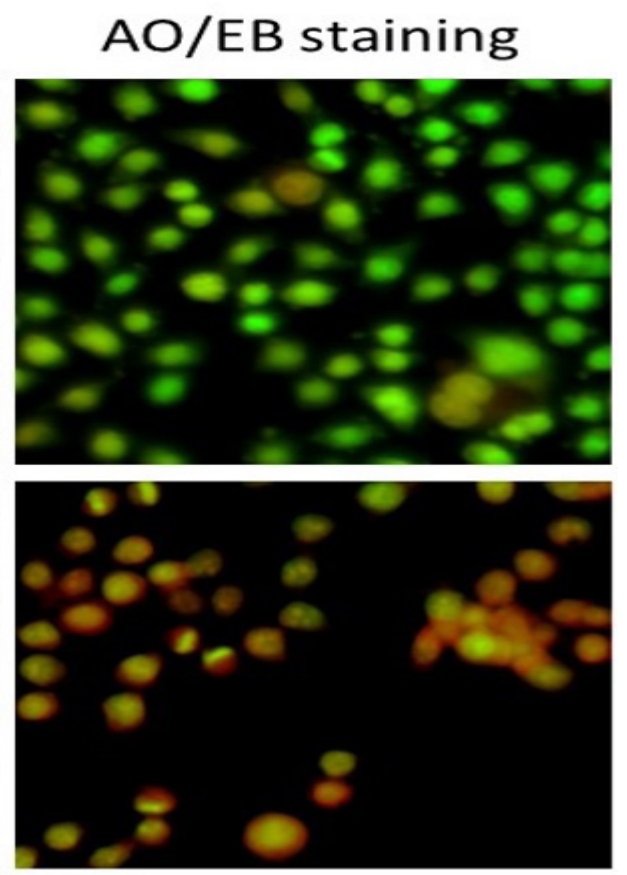

Figure 3: Cell morphology obtained by light field microscopy after incubation for 24 hours in HeLa cell line with IC50 dose of SWE and solvent (Control), apoptosis image obtained with Acridine orange/Ethidium Bromide staining FITC and Texas Red filter.

As Figure 3 shows, cell morphologies were different between the control and SWE groups. Especially in the SWE group, not only the density of the cells was decreased but also the shape of cells differed and became smaller and gemmiferous. In $\mathrm{AO} / \mathrm{EB}$ staining, alive and healthy cells were green fluorescence while necrotic cells were only red fluorescence, apoptotic cells were green and red or orange fluorescence. As it is seen in Figure 3, SWE caused a greater number of apoptotic cells by comparison to the control group in HeLa cell line. The same phenomenon was identified in nuclear staining, especially after the SWE application, nuclear morphologies of HeLa cells were impaired and apoptotic bodies became clear to see. Cell Event Caspase 3-7 molecular probes specifically bound to Caspase 3 and Caspase 7 proteins were detected extensively in cell lines subjected to SWE application and showed a dense apoptosis (Figure 4).

We also investigated the effects of SWE on HeLa cells in mitochondrial apoptosis pathways by gene expressions. The results were given in Figure 5 and 6 . 
CM-H2DCFDA
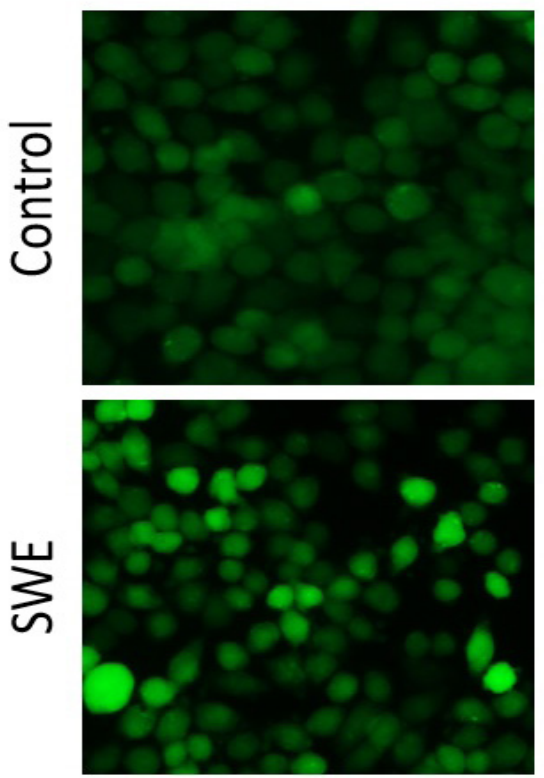

NucBlue ${ }^{\circledR}$ Live
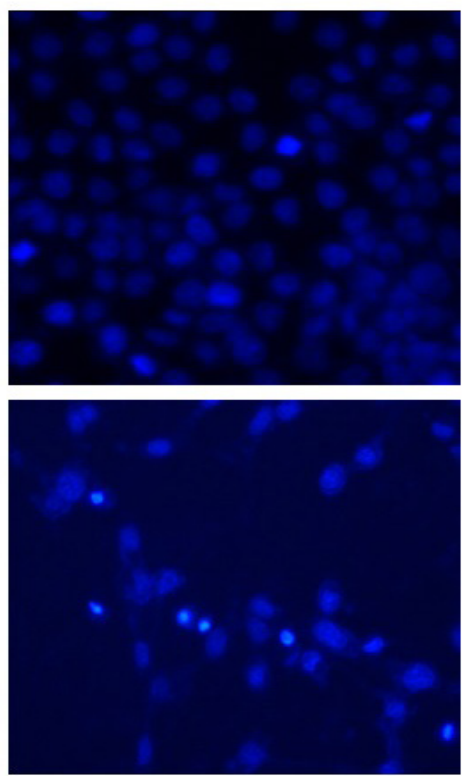

CellEvent $^{\mathrm{Tm}}$

Caspase-3/7
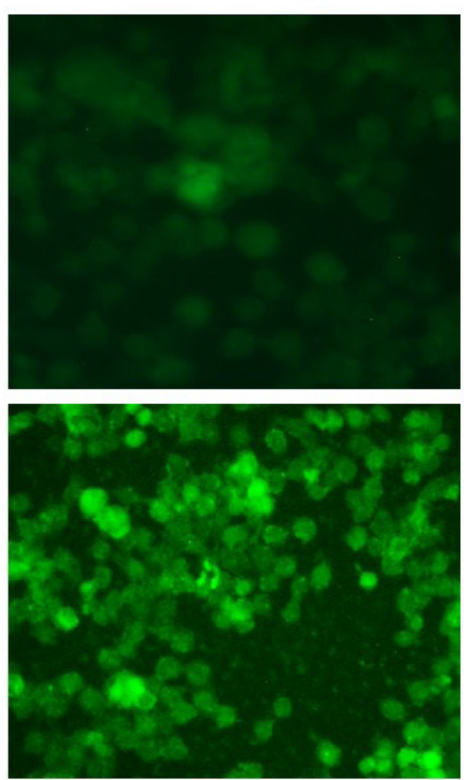

Figure 4: Images obtained by fluorescent staining with oxidative stress (CM-H2DCFDA), nuclear apoptosis (NucBlue ${ }^{\circledast}$ Live ReadyProbes ${ }^{\circledast}$ ) and caspase-dependent apoptosis (CellEvent ${ }^{\mathrm{Th}}$ Caspase-3/7 Green Detection Reagent) molecular probes in HeLa cell lines after the application of SWE in the IC50 dose.
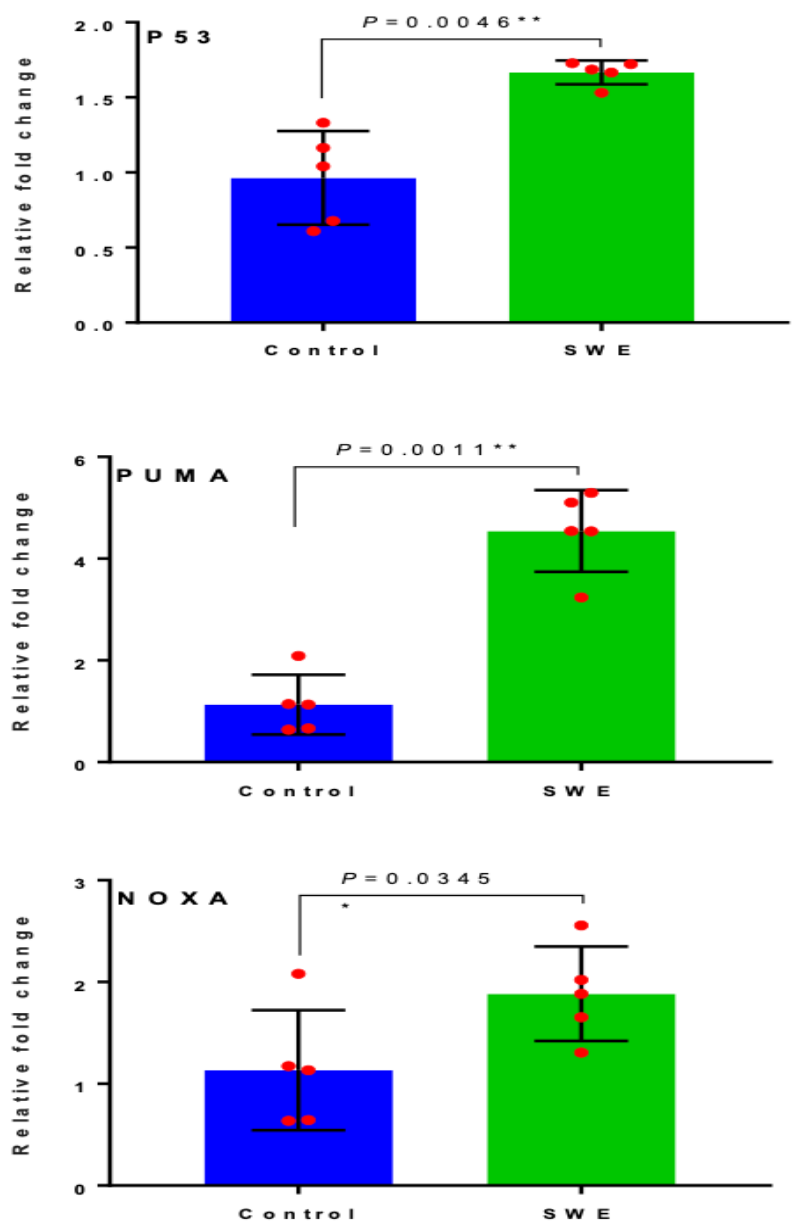

Figure 5: The effect of SWE on IC50 dose and solvent (control) application for 24 hours in HeLa cell line on P53, PUMA, and NOXA gene expressions. Data: mean \pm standard error; relative fold increase was normalized by Actin- $\beta$ gene expression. ${ }^{\star}$ Data is statistically significant $P \leq 0.05,{ }^{*}$ Data is statistically significant $P \leq 0.01$, Student's T-test. 
The spider web extract application increased tumor suppressor p53 gene expression (1.6 fold) at a statistically significant level ( $\mathrm{p}=0.0046$, Figure 5) after 24 hours. Similarly, Puma (4.54 fold) and Noxa (1.88 fold) gene expressions associated with p53 gene expression increased at a statistically significant level $(p=0.0011, p=0.0345$ respectively) (Figure 5). However, there was no statistically significant increase in BCL 2 gene expression compared to the control. On the other hand, pro-apoptotic BAX (6.10 fold) gene expression was increased at a sig- nificant level ( $\mathrm{p}=0.0025$, Figure 6 ) compared to the control. BCL2/BAX ratio declined in the favor of BAX. Cyt-c (1.38 fold) expression was not significantly different from control, whereas Apaf 1 was overexpressed (14.83 fold). At the same time, caspase 3 (1.61 fold) and caspase 8 ( 1.76 fold) gene expressions were also increased in a statistically significant level $(\mathrm{p}=0.0078, \mathrm{p}=0.0114$ respectively) compared to the control (Figure 6). A strong mitochondrial apoptosis signaling was observed.
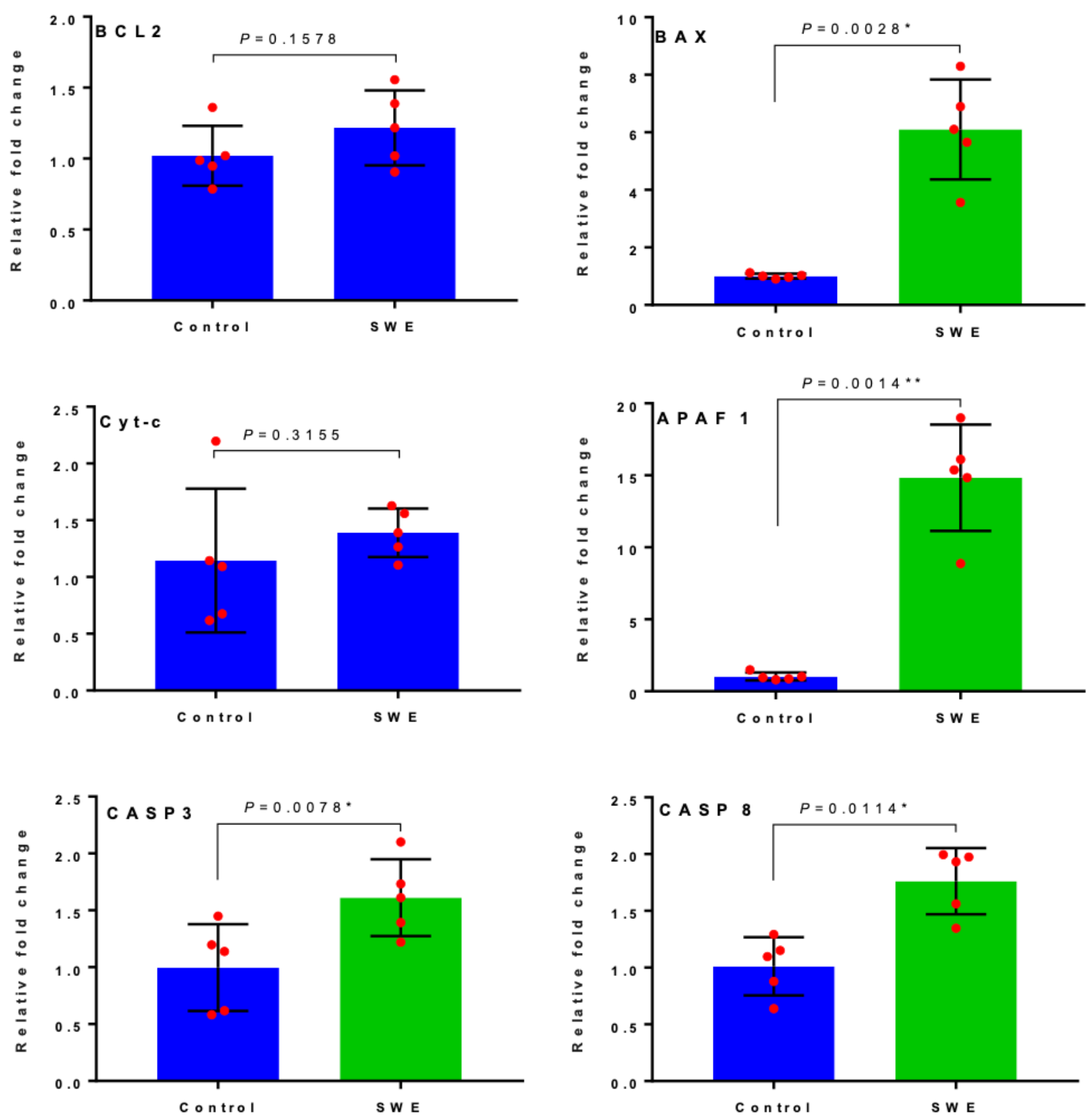

Figure 6: The effect of SWE on the IC50 dose and solvent (control) in HeLa cell line for 24 hours on BAX, Cyt-C, APAF1, Caspase 3 and Caspase 8 gene expression in the mitochondrial apoptosis signaling pathway. Data: mean \pm standard error; relative fold increase was normalized by Actin- $\beta$ gene expression ${ }^{*}$ Data was statistically significant $P \leq 0.05,{ }^{*}$ Data was statistically significant $P \leq 0.01$, Student's T-test. 


\section{DISCUSSION}

Since the existence of mankind and the development of civilization, people have benefited from many living things and their products in order to maintain a long and healthy life and to avoid diseases. With the development of modern medicine, these materials have been lost in importance for a long time, and they have become popular in search for different solutions for serious side effects of drugs. The SWE was one of those natural materials which has been used for different purposes such as healing wounds in some areas of Balkan peninsula throughout history (8). It is also used in the area of medicine as a biomaterial because of its endurance and elasticity $(7,8)$. In addition, there are various phenolic substances in spider web as mentioned before.

Naringenin and Quercetin are among the substances that are found in the spider web and they are the most known members of the flavonoid family (3). It has been reported that they have anti-cancer effect in different cancer cell lines $(1,10-22)$. Gallic acid, one of the natural phenolic compounds which is found in mostly plants that are used in Chinese alternative medicine, has dose-dependent effects of viability, proliferation and induces invasion in HeLa and other cervical cancer cell lines. In addition, it suppresses the angiogenesis $(18,19)$. Trans Caffeic Acid is also another substance that is reported to induce apoptosis and has anti-cancer effects $(21,22)$. Additionally, there are some studies which suggest that even if melatonin is a hormone in the human body, it also has anti-oxidant effects (23). All of these materials were present in the spider web which is found in our prestudy. Therefore, it can be said that spider web may be an apoptosis activator and has anti-proliferative effects. Thus, we applied SWE to HeLa cervical cancer cell line and healthy astrocyte cells in order to detect its effects.

Even if anti-neoplastic agents such as 5-fluorouracil, cisplatin, which are known as conventional in today's cancer therapies, are being used intensively, the researchers are trying to develop molecules which have specific targets, prefer specific signal pathways and effect the cellular interaction in there. While these types of molecules cause significant death effects in cancer cells, the effects on healthy cells remain at minimum (24). Almost all of the cancer drugs developed until today are derived from natural products and they are among the most studied topics (25). For this reason, we investigated the effects the effects of SWE at its IC50 dose on mitochondrial apoptosis pathway which is one of the most effective pathways in cancer cells and causes a programmed cell death, by MTT test and fluorescence staining methods. As we have mentioned before, SWE increased the expression of tumor suppressor or pro-apoptotic genes such as p53, Puma, Noxa and BAX. Therefore, it can be said that SWE caused a strong mitochondrial apoptosis signal.

As a conclusion, while spider web extract does not cause any cytotoxic effects on healthy cell lines, it causes a strong death effect in cancer cell line. In addition, we thought that IC50 dose of the spider web extract is satisfying compared to many other natural products in the market which have anti-cancer effects.

The mechanism of death effects of spider web extract on HeLa cancer cell line is not based on general toxicity. It rather causes a programmed cell death by following death signaling pathways. We determined that the resulting cell death is due to a mitochondrial apoptosis pathway in cervical cancer (HeLa). We thought that the spider web extract is a natural product worthy of further studies since it is rich in phenolic substance content.

\section{Ethics Committee Approval: N/A \\ Informed Consent: N/A \\ Conflict of Interest: The authors declared no conflict of} interest.

Author contributions: Concept: ANÖ, OD. Design: ANÖ, OD. Supervision: ANÖ, OD. Resources: ANÖ, OD. Materials: ANÖ, OD. Data collection and/or processing: ANÖ, OD. Analysis and/or Interpretation: ANÖ, OD. Literature Search: ANÖ, OD. Writing Manuscript: ANÖ, OD. Critical Review: ANÖ, OD.

Financial disclosure: This study was financialy supported by the Scientific and Technological Research Council of Turkey, 2016/2 1919B011700745.

\section{REFERENCES}

1. Luo CL, Liu YQ, Wang P et al. The effect of quercetin nanoparticle on cervical cancer progression by inducing apoptosis, autophagy and anti-proliferation via JAK2 suppression. Biomedicine \& Pharmacotherapy 2016;82:595-605.

2. Siegel R, Naishadham D, Jemal A. Cancer Statistics. Ca Cancer J Clin 2013;63:11-30.

3. Luqmani YA. Mechanisms of drug resistance in cancer chemotherapy. Medical Principles and Practice 2005;14:35-48. 
4. Persidis A. Cancer multidrug resistance. Nature Biotechnology 1999;17:94-5.

5. Özkan AN, Doğanlar O. Örümcek ağı özütünün prostat kanseri hücrelerinde seçici antikanser etkisi. TürkPatent (online) 2017 Dec (cited 2018 August 7). Available from: Available from: URL:http://online.turkpatent.gov. tr/EPATENT/servlet/PreSearchRequestManager.

6. Bhagwat S, Haytowitz DB. USDA Database for the flavonoid content of selected foods. (online) 2015 (cited 2018 August 27). Available from: URL:https://www.ars. usda.gov/ARSUserFiles/80400525/Data/Flav/Flav_R031.pdf.

7. Altma GH, Diaz F, Jakuba C et al. Silk-based biomaterials. Biomaterials 2003;24:401-16.

8. Steins A, Dik P, Müller WH et al. Müller In vitro Evaluation of spider silk meshes as a potential biomaterial for bladder reconstruction. PLoS ONE 2015;10(12):e0145240.

9. Schäfer-Nolte F, Hennecke K, Reimers K et al. Biomechanics and biocompatibility of woven spider silk meshes during remodeling in a rodent fascia replacement model. Ann Surg 2014;259:781-92.

10. Harmon AW, Patel YM. Naringenin inhibits glucose uptake in MCF-7 breast cancer cells: a mechanism for impaired cellular proliferation. Breast Cancer Res Treat 2004;85(2):103-10.

11. Jin CY, Park C, Hwang HJ et al. Naringenin up-regulates the expression of death receptor 5 and enhances TRAIL-induced apoptosis in human lung cancer A549 cells. Mol Nutr Food Res 2010;55(2):300-9.

12. Lee JH, Park $\mathrm{CH}$, Jung $\mathrm{KC}$ et al. Negative regulation of beta-catenin/Tcf signaling by naringenin in AGS gastric cancer cell. Biochem Biophys Res Commun 2005;335:771-6.

13. Sabarinathan D. Naringenin promote apoptosis in cerebrally implanted C6 glioma cells. Mol Cell Biochem 2010;345:215-22.

14. Tan M, Zhu J, Pan Y et al. Synthesis, cytotoxic activity, and DNA binding properties of copper (II) complexes with hesperetin, naringenin, and apigenin. Bioinorg Chem Appl 2009;347872-80.
15. Kim HJ, Kang JW, Kim MS et al. The apoptotic effects of the flavonoid N101-2 in human cervical cancer cells. Toxicology in Vitro 2012;26:67-73.

16. Ramesh E, Alshatwi AA et al. Naringin induces death receptor and mitochondria-mediated apoptosis in human cervical cancer ( $\mathrm{SiHa}$ ) cells. Food and Chemical Toxicology 2013;51:97-105.

17. Zeng L, Zhen Y, Chen Y et al. Naringin inhibits growth and induces apoptosis by a mechanism dependent on reduced activation of NF- $\kappa \mathrm{B} / \mathrm{COX}-2$-caspase-1 pathway in HeLa cervical cancer cells. International Journal of Oncology 2014;45:1929-36.

18. Wang Y, Zhang W, Lv Q et al. The critical role of quercetin in autophagy and apoptosis in HeLa cells. Tumour Biol 2016;37(1):925-9.

19. Zhao B, Hu M. Gallic acid reduces cell viability, proliferation, invasion and angiogenesis in human cervical cancer cells. Oncology Letters 2013; 6:1749-55.

20. You RB, Moon HJ, Han YH et al. Gallic acid inhibits the growth of HeLa cervical cancer cells via apoptosis and/or necrosis. Food and Chemical Toxicology 2010; 48:1334-40.

21. Chang CW, Hsieh $\mathrm{CH}$, Hsiao MW et al. Caffeic acid induces apoptosis in human cervical cancer cells through the mitochondrial pathway. Taiwan J Obstet Gynecol 2010; 49(4):419-24.

22. Ye JC, Hsiao MW, Hsieh CH et al. Analysis of caffeic acid extraction from Ocimum gratissimum Linn. by high performance liquid chromatography and its effects on a cervical cancer cell line. Taiwan J Obstet Gynecol 2010;49(4):266-71.

23. Bella DG, Mascia F, Gualano L et al. Melatonin Anticancer Effects: rewiew. Int J Mol Sci 2013;14:2410-30.

24. Dasari S, Tchounwou PB. Cisplatin in cancer therapy: molecular mechanisms of action. Eur J Pharmacol 2014;740:364-78.

25. Yuan R, Hou Y, Sun W et al. Naturap products to prevent drug resistance in cancer chemotherapy: a review. Ann N Y Acad Sci;1401(1):19-27. 